flammatory condition of the skin, as an eczema, such results are not uncommon.

'Tar in its several forms is extremely useful in some forms of skin disease, hut, if injudiciously used, it is eapable of producing much irritation. Like some, other drugs it camnot be used on certain skins even in very dilute applications, and in acute inflammatory conditions it must be used with the greatest care. It may produce erythematous and papular eruptions, and at times those of all erysipelatous character. 'The dermatitis maly extend some distance beyond the point of applieation. Another condition which may be produced by it is the so-called tar none. This is composed of small, hard, red papules, in the centre of each of which is a dark point. 'This condition is most abundant in the hairy portions and is very rebellious to treatment. It persists for a long time after the applications have ceased, and may take several weeks to completely resolve. ('hrysarobin is a drug nuch used in the treatment of psoriasis and some other chronic conditions of the skin. It probably causes local irritation more frequently than any other drug commonly used. It stains the sound skin a purplishli-red color but not the diseased patches. It also stains the nails and grives the hair a purple tinge. 'The dermatitis produced by it is usually erythematous, or fincly papular, but it may be more intense. I had under ny charge at the Carney Ilospital a girl with a general exfoliative dermatitis which was brought about by a few applications of an ointment containing $6 \%$ of chrysarobin. Applied to the face or sealp it is very apt to produce a violent dermatitis of erysipelatous type and maybe a conjunctivitis. I saw such a case at the City Hospital a few weeks ago. It may irritate the sebaceous glands and produce an acne like the so-called tar acne, with a black point in the centre of each papule. In applying the drug a very weak strength should be tried at first. In susceptible individuals and those with delicate skins, I have seen a 1-per-cent. ointment cause much irritation. In using an ointment, only a small amount should be applied at a time, and that well rubbed in with a swab. Otherwise the ointment is apt to get rubbed on to the neighboring sound skin, which being more sensitive than the diseased portions maly become inflamed. solutions of the drug in collodion or tramaticin dry whore they are applied, and so do not spread in this way; but they are not always suited to the condition of the skin. Of the animal irritants, the mosquito, flea, bedbug, black fly, wasp, bee and hornet are apt to make their presence appreciated, and as a rule the person afflicted makes his own diagnosis. Sometimes, however, especially in emigrants, the dermatitis produced is so extensive that it makes one suspect one of the exanthemata. I have seen an emigrant so poisoned by mosquitoes that the eruption on the exposed parts closely resembled variolit. Spiders mily drop from the ceiling during the night and cause an inflammatory condition of the face which at first sight might be mistaken for erysipelas. ('aterpillars may cause a line of erythema, wheals or vesicles where they have passed over the skin, or even deeper forms of influm mation. 'The jelly fishes which are abumlant in the salt water about here may cause much reduess of the skin, and even large wheals. I have seen a boy who got into a school of these fishes and whose body was so covered with large wheals as to suggest a giant urticaria.
NOTES ON THE TREATMEN'T OF A'TAXIC PATIEN'TS BY CO-ORDINATION EXERCISES, WITH THE DEMONSTRA'TION OF 'TWO PATIENTS. 1

BV JAMEN J. IU'NAM, M.D., HOR'TON,

'Tuk power to see the hopeful aspects of hopeless diseases is one of the best gifts of modern medicine. 'The number of maladies whose very name makes the: physician think only how he may gracefully bow the pationt from his door grows daily less; yet it is at once a warrant of the blindness in which we tread our accustomed paths and also of the hopefulness of the future that now and then the pointing out of obvious principles can claim the merit of substantial discovery. Why should the idea of training the ataxic patient to control his disorderly movements have waited for its practical development and almost for its conception until 1890, when the progress of the ataxic baby and that of the relatively ataxic school boy had been forever before us?' Obviously, the reason is that we saw only too clearly the fincl outcome of the disease and, like fatalists, let our energies be paralyzed by the prospect.

It is to 1)r. Fraenkel, a Swiss physician, that the credit of bringing the true value of this method before the profession is justly given, though Granville," and perhaps others, had long before recognized the theoretical possibility of suceess in this direction. Fraenkel's first communication, in 18:0, was followed in 1897 by a second, made before the Medical ('ongress of Moscow, at which the method was elaborated, various apparatus described and cases reported. Since then a host of physicians have brought their confirmations and criticisms, and, as is usual, the methods and the apparatus have been shown more and more to be susceptible of simplification, so that in fact the treatment in its essentials is at the commind of any physician or gymnast, or even of any intelligent person who will master the principles at stake. In saying this, I would not be understood as meaning that skill and labor are not required for the best lesults, and in fact one of the medical gymmasts who has trained several of my patients has told me that the lesson is peculiarly exhausting for the teacher.

The following points should be strictly borne in mind :

(1) It is skill, not strength, that it is sought to develop. It is indeed important that the muscles should be in a state of good vigor and healthy nutrition, and special treatment, as by massage and exercises, may be directed if necessary to that end, but so fial as the inco-ordination is concerned the need is to teach the brain and through it the lower reflex centres, to feel, and gauge, and respond to the feeble and distorted inpulses thint come from skin and joint and muscle.

(2) 'The movements, such as walking and stooping, or writing and simple piano exercises, etc., which one would freely prescribe to a healthy person, are often far too complex for the ataxic, and it is therefore necessary to begin with relatively elementary motions, such as drawing the leg up and down in bed, or moving the tinger from one spot to another. ()n the other hand, however simple the movement, the patient should be ealled upon to perform it with promptness

1 Rend before the Suffolk Diatriot Medienl Society, Section for Glinical Mediolne, Pathology and Hyglene, April $18,1900$.

'See Colline's Treatment of Nervous Disonses. Wm. Wood \& (\%o. Now York, 1800 . 
and accuracy and at the word of command. To inculcate these habits from the outset, and to reduce the difliculties at each step so that attention and effort will make success possible, and will ensure skill and confillence, are the prime requisites for a good result.

(3) Dulness, monotony and fatigue, on the one hand, and superficiality on the other, are the rocks to be avoided, both by the introduction of suflicient varicty into the exercises and by giving thom something of the entertainment of games of skill. For these reasons the exercises of putting the finger on to spots on a card or into holes on a board, as suggested by Frankel, are well modified by using marbles of various sorts or colorerl pegs, for the same purpose (as also suggested), or by giving these tasks an amusing turn, taking care, however, that the amusement occupies a subsidiary place. Simple tunes, played on a glasichord, or on bells or glasses, by calling, at varying rates of speed, the numbers indicating the notes which the patient should strike, would be in this line.

As regards the legr co-ordinations, the infinitely variable movements of walking, at the command of a prompt instructor, so many steps forward, lackward, to the right and to the left, with the eyes open, with the eyes closed (as should indeed be the eventual aim with most of the exercises); stepping over obstacles, halting, balancing and the like, furnish ample opportunity for the exercise of skill and for the training of persistence, attention and habit.

(4) 'The temptation is often strong to let the patient try to get on without any instructor, by following a set of prescribed exercises, and in the first case I treated I attempted this, using a good set of movements which had already been suggested by a colleague in another city. The result was not encouraging, however, and I should not again waste time in the effort if it was possible to get even moderately skilled assistance. 'The necessity for obedience to the word of command, which calls for close attention and for movements which come to have something of the character of involuntary reflexes, is certainly a great help in stimulating both the conscious and the subconscious attention and the power of instinctive control.

(5) Finally, there are certain classes of cases which the experience of various pliysicians has shown to be ill adapted for this sort of treatment. 'These are summarized as follows by Collins in his excellent book on the "'Treatment of Diseases of the Nervous System," page 243. "'The employment of this method of troatment is contraindicated in weak, anemic patients and in those who suffer more or less constantly with pains or crises ; in cases of acute or subacute tabes, that is, in cases of sudden onset and in which the habitual manifestations of the pre-ataxic period succeed each other rapidly; in patients with tabic optic atrophy, fragile bones and those who have had what is generally called spontaneous fracture or rupture of tendons: When any cardiopathy or ancurism exists the method must be tried very tentatively, if at all. It is not alpplicable to very obese or arthritic patients, and, finally, it is absolutely contraindicated when there are great laxity of the ligaments and severe arthropathy."

My experience is not sufficient to justify me in supporting or in contradicting these statements, but, in fact, they are not borne out by the history of the two patients whom I bring before the society tonight. The first of these has improved considerably in spite of a tendency to pretty severe pains in the legs, and the second, whose improvement has been truly remarkable, is ons in whom the ataxia developed with grent rajpidity.

'The first patient had been suffering from characteristic pains for many year's and from disorder of co-ordination for about two years. 'This had increased during the six months before he presented himself at the Massachusetts (ieneral IIospital to such a degree that he was then almost confined to his chair, though able with the and of the furniture to get about his room and shop, a little. The treatment by training in co-ordination was begun in June, 1899, but was continued for only a few months, and in a somewhat desultory mamer, owing to the necessities of the case. This year it las again been resumed. The aim was first to teach him to walk with crutches, then with canes, and this has been accomplished to such a degree that he now goes about with the aid of the forner in the neighborhood of his house quite freely, and in the way of exercises he can walk across the room alone. IIe is still improving. The treatment has been carried out faithfully in the face of considerable difficulty by Mr. Harding, the superintendent of the grymuasium of the Boston Young Men's Cluristian Üuion.

'The other patient is a much younger man, of excellent general healtl. 'The rapidity with which the ataxic symptoms came on is well indicated by the fuct that only two weeks bofore he came to me, supported by a friend on one side and with a cane in the other hand, he had been to several dances, and had walked, in the night, during a snowstorm, four or five miles to his home. Ile had, in fact, considered himself perfectly woll up to that time, though in reality some unmistakable signs of tabes had been already present. Under the guidance of Mr. Wiberg, tencher of medical gymnasties, he devoted himself assiduously to the treatment here indicated, lay by day and almost hour by hour, with the result that at the end of three months he was able to walk several miles alone or with the partial aid of a cane. Ilis gate is still ataxic, but he has recently been alble to resume his work, which without this method of trentment would have beon impossible. I may say, further, that the latter patient and one other have thought that the paresthesias from which they had suffered diminished under the co-ordinatory improvement.

\section{Elinical spepartment.}

\section{TWO CASES OF ABNORMAL, SEXUAL DEVEL- OPMENT. ${ }^{1}$}

HY GKOHES G. NISA IR, M.11., HOSTON.

Tru following cases are interesting illustrations of a condition described by recent writers under the head of infuntilism, in which more or less complete arrest of development of the grenital organs is associated with changes in the economy of a most diverse kind and inanifested by gigantism, dwarfism, fominism, muscular dystrophies, or affections of tho special senses, but about which our knowledge is still too incomplete for definite classification. In the first, im-

1 Read before the Suffolk Distrlet Medical Soclety, Section for Clinioal Modicine, Pathology and Hygione, April 18, 1800. 